\title{
Un Mito llamado Rafael Correa: la construcción de la imagen y el discurso de un caudillo neopopulista
}

\section{A Myth called Rafael Correa: the construction of the image and speech of a neopopulist caudillo \\ Um mito chamado Rafael Correa: a construção da imagem e fala de um caudilho neopopulista}

\author{
Ugo Stornaiolo Pimentel ${ }^{1}$ \\ Universidad Central del Ecuador (Ecuador) \\ upstornaiolo@uce.edu.com
}

Fecha de recepción: 06 de febrero de 2018

Fecha de recepción evaluador: 30 de septiembre de 2018

Fecha de recepción corrección: 14 de noviembre de 2018

\footnotetext{
${ }^{1}$ Ugo Stornaiolo Pimentel es Licenciado en Comunicación Social en la Universidad Central del Ecuador; Doctor de Postgrado en Ciencias Internacionales Universidad Central del Ecuador; Director de Investigación y Postgrado Facultad de Comunicación Social Universidad Central del Ecuador desde 2014. Ha trabajado como coordinador de la Carrera de Periodismo (UTE) y como docente en las Universidades San Francisco, Salesiana y de Los Hemisferios. Es columnista y editorialista de diarios nacionales e internacionales como El Comercio, Últimas Noticias, El Mercurio de Santiago de Chile, La Hora. Fue corresponsal en Ecuador de la Revista Sudamericana Visión hasta 1999. Ha sido investigador de temas nacionales e internacionales en Revistas 15 días y Criterios de la Cámara de Comercio de Quito. Fue asesor en comunicación institucional y organizacional en el Instituto Nacional del Niño y la Familia INNFA donde planificó la Campaña Nacional contra la Trata de Personas; fue director nacional de comunicación en el Programa de Protección Social PPS hasta 2009, donde planificó la campaña de Bono Fácil.
} 


\title{
Resumen
}

Este artículo tiene como base el capítulo 14 de mi texto académico "El Discurso de un Caudillo Neopopulista", de próxima circulación. En el texto se señala las diferentes estrategias que, a lo largo de diez años, se construyeron en torno a este personaje de la política ecuatoriana a quien, desde la perspectiva del marketing político y la comunicación electoral, se intentó convertir en un mito, semejante o cercano al cinco veces presidente de la República del Ecuador, José María Velasco Ibarra.

Palabras clave: Caudillismo; Mitos sociales; Neopopulismo; Política

\begin{abstract}
This article is based on chapter 14 of my academic book "The Discourse of a Neopopulist Caudillo", of forthcoming circulation. The text points out the different strategies that, over ten years, were built around this character of Ecuadorian politics who, from the perspective of political marketing and electoral communication, tried to turn into a myth, similar or close to the five times president of the Republic of Ecuador, José María Velasco Ibarra.
\end{abstract}

Keywords: Caudillismo; Social Myths; Neopopulismo; Politics;

\section{Resumo}

Este artigo é baseado no capítulo 14 do meu livro acadêmico "O Discurso de um Neopopulista Caudillo", de próxima circulação. O texto aponta as diferentes estratégias que, ao longo de dez anos, foram construídas em torno desse caráter da política equatoriana que, do ponto de vista do marketing político e da comunicação eleitoral, procuraram transformar-se em mito, semelhante ou próximo do quinto presidente da República. República do Equador, José María Velasco Ibarra.

Palavras-chave: Caudillismo; Mitos Sociais; Neopopulismo; Política; 


\section{Introducción}

Los mitos existen en todas las sociedades. Se trata de algo que tiene un argumento previamente construido y que sirve para el sostenimiento de una o varias verdades que se convierten en dogmas socialmente aceptados. Como lo señala Lucio Cerdá en su artículo "Los mitos sociales y las configuraciones subjetivas":

"El mito social sostiene una verdad incuestionable, un aserto inamovible, un hecho o conjunto de hechos que configuran una narración imposible de ser puesta en duda para aquellos que pertenecen a esa sociedad" (Pg. 3).

\section{Este mismo autor agrega:}

"No pertenecen a la racionalidad instrumental que prima en los saberes letrados. Son de otro orden, configuran una realidad diferente y no por ello menos significativa o menos legítima. Los mitos juegan un papel central en relación con la configuración de valores y creencias epocales. Son, sin duda, un fenómeno producto de los imaginarios sociales". (Pg. 3).

Como señala el académico y hombre de letras ecuatoriano Marco Antonio Rodríguez, en un artículo publicado en El Comercio de Quito, Mitos y política:

"Los mitos sofocan la realidad, pero existen: el poder es uno de ellos, y cuando este se encarna en algún ser que deviene adicto origina regímenes sátrapas y abyectos. Todo movimiento político va acumulando mitos en su tránsito histórico. El mito concluye extinguiendo al pensamiento y supliéndolo. Nulifica experiencias y desfigura hechos. Un movimiento que no es capaz de instalar sus mitificaciones en el museo del pasado está condenado a repetirse a sí mismo. La mitificación de un caudillo asuela a los pueblos. la humanidad vive la era de la transpolitización, el grado cero de lo que fue la política (vaciamiento de ideologías, derechas e izquierdas se volatizaron), no obstante, el caudillaje sigue rebrotando. Los mitos clásicos de la 'izquierda' fueron abundantes. Los más rancios y coreados: 'el hambre genera revoluciones'. No. Las revoluciones emergen cuando hay signos de cambio y surgen impaciencia y esperanza en simbiosis única. George Orwell señaló: "La democracia podría verse amenazada por ejércitos de obreros en paro capitaneados por millonarios que reciten el Sermón de la Montaña"; otro: 'el fin justifica los medios"”.

Escribíamos el domingo 27 de septiembre de 2016 en el diario La Hora un artículo con el título "Lavar la imagen", en el que citábamos algunos elementos de la fabricación del mito, con miras a la perpetuación de la imagen del caudillo de la Revolución Ciudadana (R.C.):

"Ahora que las cosas están difíciles, aparece R.C (referencia a Rafael Correa o a Revolución Ciudadana), mucho más amable. ¡Y qué bueno que es así! R.C. con un rostro agradable, seduciéndonos con la sonrisa 'kolynosesca' de hace diez años, cuando R.C. era solo un pensamiento que iba por los medios privados e independientes (entonces muy solidario con ellos) para vender su idea.

Hace poco, R.C. era uno. Ahora, por arte de birlibirloque, es otro. Volvió a sonreír. Algo necesario para la campaña presidencial ad portas del 2017. Y nada será completo con las cosas como están. Hay que buscar dinero donde sea, incluso en Washington (donde están los antes aborrecidos representantes de la "larga, oscura y triste noche neoliberal").

Con el lavado de imagen todo es posible. Los clientes y creyentes del credo de R.C. necesitan que se les diga que "todo está bien" y que las denuncias provienen de la 
"prensa corrupta", los "tirapiedras" o los "mismos de siempre”. ¿Hasta cuándo, compañeritos?...

La reputación se construye en muchos años y se destruye en pocos minutos. Algo deben saber los asesores de R.C., porque el cambio de imagen es evidente. Pero, ahora, hasta la sabatina aburre... Las estrategias del buró de marketing son claras: la culpa no es de R.C., sino de los que lo antecedieron. Fue la prensa corrupta que desinformó a la gente. Tienen tantos medios propios, ¿es posible que eso pase?

Otra estrategia fue el diálogo, pero a su manera. Este instrumento de negociación fue usado para demostrar que R.C. tiene la razón. La protesta por las leyes de herencias y plusvalía fue por desinformación. ¿Hasta cuándo compañeritos?

Hay que detenerse en el mayor producto publicitario de la marca R.C.: "Cuiden la credibilidad del Presidente, que es el mayor tesoro que tiene la revolución". Puede ser que haya división entre quienes quieren y no quieren a R.C., pero "todos le creen".

Es posible que R.C. crea que le creen, con toda la buena fe. Sin embargo, hay demasiados frentes abiertos, faltan los recursos, hay desconfianza y desengaño y el país ha entrado en una espiral de incredulidad, agravada por fenómenos naturales, pero "hay que cuidar el mayor tesoro". Aclaración: R.C. son las siglas de 'revolución ciudadana'."

Fabricar seres mitológicos en la cultura política latinoamericana ha sido una especie de fijación, a partir de la relación entre algún caudillo y los conglomerados sociales. Pasó con Rafael Leonidas Trujillo en República Dominicana, con el general Juan Domingo Perón en Argentina o con José María Velasco Ibarra en Ecuador. Pero ¿cómo entender la coyuntura actual sin mencionar al caudillo argentino de mediados del siglo $\mathrm{XX}$ ?

En su trabajo doctoral titulado "Perón: La Construcción del Mito Político (19431955) (2010), en la Universidad de La Plata (Argentina), Alicia Estela Poderti hace algunas anotaciones sobre el fenómeno del caudillo argentino:

"En su libro Los estratos del tiempo (2001), Reinhard Koselleck estudia la dinámica de la circularidad de los tiempos históricos y las estructuras de repetición a las que hemos aludido. Un mito político se construye a partir de narraciones e imágenes sobre sucesos, personajes e ideas que determinan el comportamiento y la orientación social marcada por una sugestiva "fascinación". Se trata aquí de narraciones e imágenes que se remiten a los orígenes, al sentido y a la misión de una comunidad. El mito político implica la legitimación del orden constituido $\mathrm{y}$, a la vez, coadyuva a la integración de la comunidad viviente, dentro de ese orden preestablecido y aceptado. Esta es la base que otorga consistencia y estabilidad a la comunidad. Así como las instituciones políticas estarían destinadas a evitar los efectos desestabilizadores que pueden producir una brusca metamorfosis, el mito político es la condición que se requiere para lograr la cohesión y sentimientos de adhesión de los grupos sociales". (pág. 18)

\section{Desarrollo}

Para la construcción del mito Rafael Correa es indispensable revisar a otros personajes que fueron una creación de las maquinarias políticas en sus países, generalmente caudillos latinoamericanos: el mismo Juan Domingo Perón, Hugo Chávez o los esposos Kirchner, entre otros. Coincidentemente, Chávez y los Kirchner también son parte de la corriente del "socialismo del siglo XXI", hoy en franco declive. 
Un autor que estudia detenidamente el fenómeno de los mitos cotidianos es el francés Roland Barthes, en su obra "Mitologías", donde explica que cualquier fenómeno o personaje de la vida cotidiana puede ser mitificado, incluyendo a la patata frita o a las divas del cine. Barthes analiza de una manera simple la transformación entre la realidad y lo que ésta representa:

"Acabamos de ver que el buen sentido poujadista consiste en establecer una equivalencia simple entre lo que se ve y lo que es. Cuando una apariencia es decididamente muy insólita, a ese mismo sentido común le queda un medio de reducirla sin salir de la mecánica de las igualdades: el simbolismo. Cada vez que un espectáculo parece inmotivado, el buen sentido echa a andar la pesada caballería del símbolo, admitido en el cielo pequeñoburgués en la medida en que, a pesar de su vertiente abstracta, une lo visible y lo invisible bajo las especies de una igualdad cuantitativa (esto vale esto): el cálculo se salva, el mundo resiste todavía”. (pág. 49)

Su capítulo de la Gramática Africana nos ofrece algunas coincidencias con el momento político ecuatoriano y latinoamericano contemporáneo (algunas de las definiciones van desde la página 77 a la 80 ):

DESTINO. "No es la conquista militar la que sometió Argelia a Francia, sino una conjunción operada por la Providencia que unió dos destinos. Fraseología: "Por nuestra parte, pretendemos dar a los pueblos cuyo destino está ligado al, una independencia auténtica dentro de la asociación voluntaria" (Pinay en la ONU). (pg.77)

La doctrina presupone que para fabricar el mito se debe unirlo a la idea de un destino indisoluble entre el líder o la nación y su pueblo. La idea que subyace es que “después de mí, el diluvio".

DIOS. Forma sublimada del gobierno francés. Fraseología: “... En la medida en que el Todopoderoso nos ha designado para ejercer el cargo supremo..." (Declaración de Ben Arafa). "... Con la abnegación y la soberana dignidad con que siempre ha dado ejemplo... Su Majestad entiende obedecer, de esta manera, los designios del Altísimo..." (Carta de Coty a Ben Arafa, cesado por el gobierno). (Pg. 78)

En este caso, para crear el mito se debe creer en una especie de divinidad del líder, para que sus actos y palabras sean de un valor supremamente grande. Por ejemplo: "Cuiden la credibilidad del Presidente, que es el mayor tesoro que tiene la revolución" (sabatina presidencial 441).

GUERRA. El objetivo es negar el problema. Para ello se dispone de dos medios: o bien nombrarla lo menos posible (procedimiento más frecuente), o bien darle el sentido contrario. Guerra se emplea entonces en el sentido de paz; y pacificación, en el sentido de guerra. (Pg. 80)

En el caso de la palabra anterior, la guerra no es un asunto de armas, tecnología y campos de batallas, sino de enfrentamientos ante quienes se oponen a los postulados de la revolución ciudadana y se busca aminorar los términos que se expresan:

El presidente Rafael Correa declaró durante la sabatina, realizada en La Libertad (sábado 30 de enero de 2016, nota del autor), que no existe crisis económica. Dijo que "otra cantaleta" que según él la oposición trata de posicionar, es que su régimen "no ha hecho nada para enfrentar la crisis". 
"Yo ya me cansé... "Llámele como le dé la gana, crisis, recesión. Académicamente, sabemos que no estamos en crisis", ha dicho. "Si politiqueramente quieren llamarla crisis... ¡ eehh! ¡En buena hora que sean así las crisis!, ¿no? Porque la crisis del 99, que fue por culpa de ellos, acá tenemos derrumbe del precio del petróleo, un contexto internacional terrible. La crisis de 1999 fue por desregular a la banca, por el neoliberalismo. ¡Eso fue crisis! Decreció 6\% el PIB. El desempleo aumentó a 16\%. ¿Qué bueno esta crisis de ahora en que crecemos el $0.4 \%$ ! Que tenemos desempleo de $4.7 \%$. Este es otro logro de la revolución ciudadana" (sabatina 460).

Ese fue uno de los episodios más comentados al negar la crisis en un panel ante economistas "de oposición” y cercanos excolaboradores (miércoles 28 de octubre del 2015), en donde negó que hubiese crisis en el Ecuador, aduciendo que toda la causa está en la baja de los precios de las materias primas, como el petróleo y la depreciación del dólar, moneda en curso legal en el Ecuador, que impide que se tomen medidas de tipo de cambio. La frase textual del mandatario: "Es falso que estamos en crisis... crisis hubo cuando dos millones de ecuatorianos tuvieron que migrar...”.

Y otra de sus frases, en un encuentro ante periodistas también considerados como "opositores" (Alberto Padilla) o cercanos simpatizantes (Carlos Rabascall) (12 de enero de 2016), en donde esta frase causó mucha hilaridad entre seguidores y opositores y se convirtió en una tendencia en redes sociales:

“... antes del Gobierno (el país) era como las familias que vivían en casas de caña, en terreno ilegal, sin salud y ni educación, y encima si el jefe de familia perdía el empleo se quedan en la miseria sin tener qué comer. Pero ahora es como una familia de clase media, que tiene casa de cemento con dos pisos, terreno legalizado, un auto, educación, salud y si el jefe de familia se queda sin empleo, "tiene la tarjeta de crédito para seguir subsistiendo".

Desde entonces, el mejor medio de pago, aunque no aceptado en ningún establecimiento comercial, es "mashicard" (tarjeta de crédito del mashi Rafael).

Sigamos leyendo a Barthes, en su obra Mitologías (pág. 90):

"Fotogenia Electoral: Algunos candidatos a diputado adornan con su retrato sus folletos electorales, lo que presupone que la fotografía tiene un poder de conversión que es necesario analizar. Ante todo, la efigie del candidato establece un nexo personal entre él y los electores; el candidato no sólo da a juzgar un programa, sino que propone un clima físico, un conjunto de opciones cotidianas expresadas en una morfología, un modo de vestirse, una pose. De esta manera, la fotografía tiende a restablecer el fondo paternalista de las elecciones, su naturaleza "representativa", desordenada por la representación proporcional y el reino de los partidos (la derecha parece usarla más que la izquierda).

En la medida en que la fotografía es elipsis del lenguaje y condensación de un "inefable" social, constituye un arma anti intelectual, tiende a escamotear la "política" (es decir un cuerpo de problemas y soluciones) en provecho de una "manera de ser", de una situación socio moral. Se sabe que esta oposición es uno de los mitos mayores del poujadismo (Poujade en la televisión: "Mírenme: soy como ustedes"). La fotografía electoral es, pues, ante todo, reconocimiento de una profundidad, de algo irracional extensivo a la política. Lo que atraviesa la fotografía del candidato no son sus proyectos sino sus móviles, las circunstancias familiares, mentales, hasta eróticas, todo ese modo de ser, del que a la vez es producto, ejemplo y estímulo. Es claramente perceptible que lo que la mayoría de nuestros candidatos da a leer en su efigie es su posición social, la comodidad espectacular de normas familiares, jurídicas, religiosas, la propiedad infusa 
de ese tipo de bienes burgueses, como, por ejemplo, la mesa del domingo, la xenofobia, el bistec con papas fritas, la comicidad del cornudo, en resumen, lo que se llama una ideología".

Barthes lo complementa, más adelante, cuando habla de la construcción del mito en la vida cotidiana (pág. 108):

"El mito es un habla. Claro que no se trata de cualquier habla: el lenguaje necesita condiciones particulares para convertirse en mito. De estas condiciones hablaremos en seguida. Pero lo que desde ya sabemos plantear como fundamental es que el mito constituye un sistema de comunicación, un mensaje. Esto indica que el mito no podría ser un objeto, un concepto o una idea; se trata de un modo de significación, de una forma. Más adelante habrá que imponer a esta forma límites históricos, condiciones de empleo, reinvertir en ella la sociedad; nada impide, sin embargo, que en un principio la describamos como forma. Sería totalmente ilusorio pretender una discriminación sustancial entre los objetos míticos: si el mito es un habla, todo lo que justifique un discurso puede ser mito. El mito no se define por el objeto de su mensaje sino por la forma en que se lo profiere: sus límites son formales, no sustanciales. ¿Entonces, todo puede ser un mito? Sí, yo creo que sí, porque el universo es infinitamente sugestivo".

Para entender la construcción de los mitos, es necesario, como lo mencionábamos al inicio del capítulo a personajes que han tenido un paralelismo con Rafael Correa. El principal es Hugo Chávez, uno de los mayores inspiradores de la vida política de Correa. ¿Qué se decía en el editorial "Chávez: la construcción de un mito", publicado en el diario Nueva Tribuna de España, ¿en el 2013?

"Las circunstancias y repercusiones de la muerte de Hugo Chávez posiblemente no encuentren otro antecedente que la desaparición de Evita. Las masas que se han movilizado, incluso el anuncio del fallecimiento de ambos -se usó la misma expresión: en el momento de dar cuenta de la hora de la muerte, se dijo que en ese momento habían entrado en la inmortalidad-, todo apunta a un mismo fenómeno. El Mesías de los pobres -Chávez-, recuerda a la abanderada de los descamisados -Evita-, de una forma indiscutible.

Será embalsamado y se le exhibirá en el Museo de la Revolución. No en vano Chávez se declaró admirador del peronismo, movimiento con el cual tuvo numerosas similitudes. Chávez y Perón fueron militares, de origen humilde, que antes de pasar por las urnas participaron en movimientos golpistas contra gobiernos civiles. Con importantes recursos retóricos, ambos lograron entusiasmar a las masas. Y la bonanza económica -Perón se encontró con los pasillos del Banco Central lleno de oro, Chávez coincidió con un alza muy importante del precio del petróleo- les permitió repartir a manos llenas entre los descamisados y los habitantes de los ranchos miserables que pueblan los cerros que rodean Caracas".

Y si Chávez fue un referente, también lo han sido los esposos Kirchner, el ya fallecido Néstor y su esposa Cristina, ex presidentes de Argentina por un largo lapso (2003-2016) en el artículo "Los Kirchner, la construcción de un mito":

"En esa propensión exagerada al culto de figuras dominantes, la fisonomía del actual oficialismo se confunde con las inclinaciones notorias de otros movimientos políticos. La del fascismo, tan presente en la hora fundadora del peronismo. La del estalinismo, que alimentó las fantasías más juveniles de figuras que han terminado, con el paso de los años, por recalar, sin explicación alguna de su pasado, en el movimiento "nacional y popular" que gobierna desde 2003. La del castrismo, que ha envenenado a 
generaciones de latinoamericanos, como ahora lo hace el chavismo, con la dialéctica del atraso y la violencia que pregona y práctica".

¿Y qué pasaba en tiempos del general Juan Domingo Perón? Acaso el mayor ícono de la personificación del caudillo en un mito y haciendo una comparación con lo que se hizo en el período de los Kirchner:

"Tanto empeño por sacralizar a un caudillo no debe ser justificado, pero sí puede ser comprendido. Es, en principio, consecuencia del nepotismo. Así como contamina el organigrama institucional con vinculaciones privadas, esta deformación busca imponer en la esfera colectiva sentimientos emocionales que pertenecen a la intimidad familiar.

Aquí y hoy, quien ocupa la primera magistratura no sólo es la heredera de un legado político; también es la viuda del exfuncionario fallecido. Su historia conyugal se entrelaza, entonces, con la vida del Estado. Es previsible, aunque no tolerable, que alguien envuelto en esa confusión termine oficializando los dolores propios. Desviaciones de esa naturaleza hunden sus raíces en la historia nacional moderna. Especialmente en la del partido gobernante.

Además de haber hecho desde temprano un culto de su fundador, como quedó reflejado en la letra de "Perón, Perón, qué grande sos, mi general, cuánto valés", el peronismo involucró en un tiempo a toda la comunidad en los lutos de facción. No hace falta recordar la severidad con que esa operación se llevó adelante cuando sobrevino la muerte de María Eva Duarte de Perón, en julio de 1952".

Fue un duelo sentido por millones de argentinos, pero que se impuso a otros a palos. El empleado público que evadía ponerse la corbata negra de rigor en aquellos tiempos quedaba en la calle. Al insistir, pues, en la socialización de su duelo, el oficialismo de estos días obedece al mandato de aquella tradición que otros peronistas más peronistas, en realidad, que kirchneristas- han dado por superado".

Para uno de los antiguos simpatizantes de Correa, el ex asambleísta, ex concejal de Quito y excandidato a la presidencia, Norman Wray (quien, es bueno recordar, aparece en un video en tiempos del presidente Gutiérrez, junto a Correa durante las protestas callejeras de abril y mayo de 2005). Wray sostiene que Correa ya es un mito:

"Se ha construido un fenómeno mediático, político y comunicacional de enormes proporciones que ha venido generando una estrategia en la cual existe un liderazgo exclusivo donde todos los demás deben ceder al discurso de ese liderazgo. Y eso no es democracia interna, pero tampoco externa".

¿Cómo se va construyendo el mito Rafael Correa? La autora Caroline Ávila Nieto describe y hace un seguimiento de este tema en su artículo "El mito como elemento estratégico de comunicación política: aplicación del modelo de Barthes al caso ecuatoriano". En este texto relata la apropiación de Correa de un importante mito histórico del país, el general Eloy Alfaro:

"Eloy Alfaro representa, para la mayoría de los ecuatorianos, la Revolución Liberal. Los libros de historia de primaria y secundaria así lo posicionan y, posteriormente, los medios de comunicación ratifican en su discurso la asociación de Alfaro con el cambio radical de su propuesta de modernidad (Ministerio de Educación del Ecuador, s.f.). Esta imagen de revolución se asocia también con la forma como llegó al poder, a través de las montoneras que lideró por treinta años: de ahí su sobrenombre de "viejo luchador"'. (pág. 144) 
En este trabajo se establece asociaciones, perpetradas como inevitables entre el caudillo de la Revolución Liberal y su pariente lejano (como se ha mencionado en algunos capítulos anteriores).

"Los conceptos de lucha y revolución van muy de la mano en la gestión de Alfaro. La revolución de Alfaro, sin embargo, no está exenta de obras. La principal imagen asociada a su gestión, como ya se dijo, es el ferrocarril, que representó principalmente la unión entre la costa y la sierra. Un segundo referente es la educación laica como símbolo de inclusión, de alterar el statu quo y procurar mayor acceso a los derechos fundamentales. También se asocian con Alfaro su procedencia, Montecristi, pequeño pero importante poblado de la provincia de Manabí, y, claro está, su asesinato, denominado por los historiadores como la Hoguera Bárbara en referencia a su cruel arrastre y posterior quema de sus restos que tuvo lugar en El Ejido, en la capital, Quito, y que simbolizan el desenlace de un permanente ataque por parte de sus enemigos: la aristocracia quiteña, la burguesía guayaquileña y la línea moderada de los liberales". (pág. 144)

$\mathrm{Al}$ anterior simbolismo, esta autora agrega términos asociados como revolución, cambio, transporte, educación, justicia, enemigos, lucha, entre otros, que son acogidos por el discurso correísta, al referirse al "Viejo Luchador" y lo que él simbolizaría, ser el "nuevo luchador".

"El equipo de comunicación del presidente Rafael Correa aprovecha esta asociación y construye sobre Eloy Alfaro un conjunto de valores que dan forma a su discurso estratégico de Revolución Ciudadana”. (pág. 144)

Finalmente, se trata de construir un nuevo mito a partir del anterior, para así dejar marcada cierta línea de continuidad:

"Desde la campaña electoral de 2006, el concepto de revolución tuvo siempre eco en referentes relacionados: la lucha, el cambio, la nueva constituyente, etc. Ya en el gobierno, la estrategia de comunicación asoció los principales hitos de su gobierno con referentes de Alfaro: Montecristi, con la nueva Constituyente; el concepto de lucha y la arenga militar, la reconstrucción vial y la restauración de la locomotora”. (pág. 144)

\section{Conclusiones}

La investigación abarcó innumerables fuentes bibliográficas, humanas, video gráficas y hemerográficas, donde nos hemos podido percatar que la secuencia histórica de los personajes muchas veces se ve atravesada por la fuerza de sus argumentaciones y una complicada intrepidez en sus palabras.

Pero, pocas veces, en los análisis efectuados, se ha encontrado un personaje tan complejo en sus frases y en sus actuaciones, por la sumatoria de contradicciones en las que ha caído en un lapso de no más de diez años, desde que hizo su aparición en la escena política, hasta los tiempos actuales. Aunque en la historia política ecuatoriana tiene pocos personajes a los que se podría calificar como míticos, Correa va a intentar entrar en ese grupo.

Al igual que García Moreno, Eloy Alfaro, Juan José Flores y José María Velasco Ibarra, la presencia de Rafael Correa en la presidencia del Ecuador no puede pasar inadvertida, precisamente porque con este mandatario se ha "reinaugurado" el viejo estilo de hacer política (el del caudillismo y del populismo) pero sustentado por las nuevas 
tecnologías de la información y la comunicación (TICs) que Correa y su equipo de asesoría manejan con mucha solvencia, corroborando las tesis que manejaba, desde la década de los 90, el pensador italiano Giovanni Sartori en su obra "Homo Videns" (1998), donde señalaba que el ser humano contemporáneo está imbricado con la comunicación visual, especialmente, que es la que prevalece, fundamentalmente entre las nuevas generaciones. Es decir, el "tecnopopulismo", del que hablan Carlos De la Torre Espinoza y Rodrigo Borja Cevallos, al que nosotros denominamos "tecnoroldosismo". De ahí, a fabricar el mito hay mucha distancia.

Las variables del discurso tienen la importancia de hacernos notar ciertos elementos que son consistentes y otros que dejan de serlo y lo vuelven a ser repentinamente. Todo es de acuerdo "al cristal con que se mira" ...

Es muy decidora la parte de la investigación en la que se hace un seguimiento del apego o desapego del mandatario - de acuerdo con conveniencias y coyunturas- a las tesis del Socialismo del Siglo XXI, a las que se adhiere al inicio de su mandato y que va eliminando hasta el séptimo año y que, súbitamente, vuelven a reaparecer en un evento político de grupos progresistas en el tercer semestre de 2014, dejando pocas luces sobre la real ideología del personaje (que pasa de católico progresista, enemigo de las trasnochadas ideas de la teología de la liberación, al socialismo del siglo XXI o del buen vivir, hasta el capitalismo moderno de René Ramírez..)

Los eslóganes de campaña (por cierto, Correa estuvo en campaña permanente desde el 15 de enero del 2007, cuando comenzó su prolongado mandato) se fueron modificando de acuerdo a las coyunturas y las frases que se utilizaron repetidamente y de manera indiscriminada en cualquier escenario ("la prensa corrupta, la triste, oscura y larga noche neoliberal, los sicarios de tinta, los odiadores, los sufridores, los tirapiedras, los mismos de siempre, la restauración conservadora, el pasado, el socialismo del siglo XXI o del buen vivir"), que son elementos que se convierten en ejes transversales de un discurso y una puesta en escena cargados de emotividad, apelando a la vieja retórica de Aristóteles, en donde era más importante la persuasión que el discurso en sí mismo.

Algunas disciplinas como la semiótica, la lingüística y la sociología no bastan para explicar las afirmaciones y puestas en escena del discurso correísta, que presentan rasgos, no solo de discurso verbal y textual, sino de códigos sociales que se han ido construyendo a lo largo de estos casi diez años de presencia y exposición mediática y no mediática del personaje analizado, intentando fabricar ese mito en las palabras y en las actuaciones.

Es importante hacer notar que este trabajo no se pretendía hacer una crítica per se del personaje, por las simpatías o antipatías personales que podrían existir que, sin embargo, no fueron obstáculo para efectuar un tratamiento muy serio y objetivo en esta investigación. Para lo otro consta los apologistas y los detractores, que han existido a lo largo de la existencia de esta república y desde tiempos inmemoriales y que han escrito a favor y en contra de aquellos personajes que han dejado huella y que han logrado una trascendencia - para bien o para mal-. 
Correa es definido como un caudillo y esto ha podido ser demostrado a lo largo del estudio, con evidencias muy claras y, sobre todo, gracias a las opiniones de connotados analistas que lo han ubicado en esa especie de pedestal caudillista que sigue encabezando, todavía - no faltaba más-, el cinco veces presidente de la República, José María Velasco Ibarra.

Correa es neopopulista o tecnopopulista, porque su ideología no ha podido ser determinada ni por sus acciones de gobierno ni por sus antecedentes de lucha política, ya que su vida estuvo ligada a lo académico -incluyendo viajes de estudio en el exteriorhasta que hizo irrupción en la política, hace diez años. No se recuerda de él ningún episodio de salida a las calles (una corta aparición en las protestas contra Lucio Gutiérrez es lo único destacable), prisión e incluso situaciones de amenaza de muerte, por expresar sus ideas, como sí ocurrió en el pasado con personajes como Alfaro, García Moreno, Roldós, los Arosemena, Hurtado, Borja y hasta el mismo Velasco Ibarra.

Es un personaje que fue construyendo su lucha, no desde las trincheras de la política partidista a la que dice detestar, sino desde el ejercicio del poder, que es desde donde fue cimentando su imagen de redentor político y refundador del país, intentando recrear el personaje mítico e indispensable que fue Velasco Ibarra, catalogado como el "gran ausente" cuando partía exiliado del país. Al partir a Bélgica luego de su presidencia, el mito Correa se ha ido desmoronado poco a poco, demostrando la fragilidad de la memoria política en el país. En dos ocasiones, entre diciembre de 2017 y enero de 2018 ,

Correa ha tenido que regresar algunas veces al país para tratar de salvar lo que queda de su movimiento político, bastante desgastado tras los procesos por corrupción que se han seguido contra sus ex colaboradores, especialmente contra el defenestrado y sentenciado ex vicepresidente Jorge Glas, y para hacer campaña a favor del NO en la consulta popular convocada por su sucesor -hoy su rival, luego de haber sido su binomio en 2006 y 2009-, Lenin Moreno, donde se planteó al pueblo la eliminación de la enmienda constitucional de diciembre de 2015 sobre la reelección indefinida, mecanismo que han utilizado otros caudillos de la región, como Ortega, Maduro y Evo Morales, para perpetuarse en el poder.

En esta parte hay que señalar que, aunque su discurso y la creación de su caudillismo tuvieron a la "partidocracia" como su principal rival, existen evidencias muy claras de una vinculación de Rafael Correa a los movimientos políticos que existieron en el país en su temprana juventud, a los que ahora detesta y denosta.

Para señalar lo anterior: su amistad con su compañera de aulas universitarias Martha Roldós, hija del fallecido presidente Jaime Roldós (hay una foto que testimonia que asistió a la boda de ella), una fotografía en un cóctel junto con el ex presidente Oswaldo Hurtado y su fuerte vínculo con círculos de oración y acción política del ex presidente Gustavo Noboa (los "gustavinos", de los que también fue parte su ex secretario jurídico Alexis Mera e indirectamente su ex ministro y asesor Ricardo Patiño), dan a entender ciertos acercamientos y simpatías con ciertas corrientes demócrata-cristianas, socialdemócratas e incluso de grupos cristianos cercanos a la extrema derecha (se podría decir incluso social-cristianos y conservadores). 
Está bastante claro que Rafael Correa no estuvo en el país cuando ocurrieron los lamentables sucesos de 1999, donde el país se sumió en el caos económico durante el gobierno de Jamil Mahuad, que devino en la crisis bancaria, la fuga de capitales y la dolarización, pues estaba estudiando en el exterior. Cierto es, tenía 36 años, y no se le podía pedir otra cosa y es bastante poco probable que haya tenido un conocimiento de primera mano de lo que estaba sucediendo en el Ecuador.

Quedan algunas interrogantes sobre algunos episodios de su vida que, quizás, algún panegirista podría comparar con los "años desconocidos de Jesús de Nazaret" en los que el caudillo neopopulista no tuvo ninguna participación en la vida nacional, lo que no sería criticable, tomando en cuenta que estaba en el exterior aprovechando becas de estudio que obtuvo, gracias a personajes políticos y académicos a quienes él luego, al devenir en político, despreció (caso Gustavo Noboa Bejarano). Pero de llegar a ser un mito, es muy poco lo que se puede decir respecto a Rafael Correa.

\section{Referencias}

Ávila Nieto Caroline, El mito como elemento estratégico de comunicación política: aplicación del modelo de Barthes al caso ecuatoriano", publicado en Cuadernos Info en el enlace http://cuadernos.info/index.php/CDI/article/view/cdi.31.447/pdf

Barthes Roland: Mitologías (1999), Siglo XXI Editores, México D.F.

Cerdá Lucio (1998) Los mitos sociales y las configuraciones subjetivas publicado en el diario www.abc.gov.ar/lainstitucion/RevistaComponents/.../4_cerda_st.pdf) (revisado el 20 de febrero de 2016).

Correa, Rafael, Enlace Ciudadano 460, del sábado 30 de enero de 2016.

Correa, Rafael, Enlace Ciudadano 441, del sábado 12 de septiembre de 2015.

Correa Rafael, Entrevista televisada el 12 de enero de 2016.

http://www.elcomercio.com/actualidad/rafaelcorrea-debate-economia-finanzascrisis.html (revisado el 4 de febrero de 2016).

Diario La República (2016), Artículo “Correa dice que académicamente no estamos en crisis", publicado en el link http://www.larepublica.ec/blog/politica/2016/01/31/correa-diceacademicamente-no-estamos-crisis/ (revisado el 3 de febrero de 2016).

http://www.metroecuador.com.ec/noticias/academicamente-no-estamos-en-crisis-dicecorrea/rUrpaE---6V46cP70P5RpI/ (revisado el 3 de febrero de 2016).

Diario La Nación de Argentina, editorial publicado en el enlace http://www.lanacion.com.ar/1340510-kirchner-la-construccion-de-un-mito (revisado el 11 de enero de 2011). 
Editorial Chávez: la construcción de un mito, publicada en el enlace http://www.nuevatribuna.es/articulo/america-latina/chavez-la-construccion-deun-mito/20130308084218089419.html (revisado el 20 de febrero de 2016).

Poderti Alicia Estel (2010), Perón: La Construcción del Mito Político (1943-1955) ediciones Universidad de La Plata, Argentina.

Rodríguez Marco Antonio, Mitos y Política (2016) publicado en diario El Comercio en el enlace http://www.elcomercio.com/opinion/mitos-politica-democraciaopinion-marcoantoniorodriguez.html

Sartori Giovanni, Homo Videns (1998), Editorial Taurus, Alfaguara, SA, Buenos Aires, Argentina.

Stornaiolo Ugo (2016), artículo Lavar la Imagen publicado en el link https://lahora.com.ec/noticia/1101867803/lavar-la-imagen- el 27 de septiembre de 2016

Wray Norman (2016), Entrevista a en diario Expreso de Guayaquil publicada en el enlace http://expreso.ec/expreso/plantillas/nota.aspx?idart=3914233\&idcat=19308\&tip $\mathrm{o}=2$ (revisada el 14 de diciembre de 2016). 